\title{
Relationship among the Urban and Rural Students' Cooperative Attitude, Creative Task Engagements and Competition Value in Participating a STEAM Co-creation Contest
}

\author{
Jon-Chao Hong, Mei-Lien Chen, Chih-Mei Wang, Jhen-Ni Ye, and Jian-Hong Ye
}

\begin{abstract}
Cooperative learning has been proven to enable learners to have a meaningful learning progression, but research on cooperative learning based on competitive situations is still rare. Therefore, based on the social interdependence theory, this research proposed six research hypotheses and a research model, and conducted a verification analysis through the structural equation model to explore the relationship between cooperative attitude, creative task engagement, and competition value. In order to achieve the research purpose, this study adopted the intentional sampling method, and invited the participants who had participated in the STEAM co-creation contest for urban and rural students in 2019 to complete the questionnaire. After deleting the invalid data, there were 163 active participants, including 114 males (69.9\%), 49 females (30.1\%), 58 urban school students (35.6\%), and 105 rural school students $(64.4 \%)$. The mean age was 11.83 years (standard deviation was 1.26 years). The research results showed that the cooperative attitude was positively correlated with the three types of creative task engagement, including behavioral engagement, emotional engagement and cognitive engagement, and the three types of creative task engagement were also positively related with the competition value. From the research results, it could be seen that the STEAM competition in which urban and rural students work together could bring good benefits. In addition to strengthening the communication between students in urban and rural areas, they could also give them a good investment in creative tasks. Based on this, it is suggested that education authorities could increase the cooperative learning opportunities for urban and rural students to participate in this type of STEAM co-creation contest.
\end{abstract}

Index Terms-PowerTech, STEAM contest, cooperative attitude, creative task engagement, competition value.

\section{INTRODUCTION}

Cultivating talents with international competitiveness in the 21 st century has become an important goal of educational reform in many countries [1], and the STEM teaching method is based on the application of knowledge across disciplines [2]. In order to effectively apply science, technology, engineering, and mathematics (STEM) education, it is necessary to prepare a link between its four core elements and

Manuscript received June 12, 2020; revised October 14, 2020.

Jon-Chao Hong, Mei-Lien Chen, Chih-Mei Wang, and Jian-Hong Ye are with the Department of Industrial Education, National Taiwan Normal University, Taiwan (e-mail: tcdahong@gmail.com, lyt129@lygsh.ilc.edu.tw may@namchow.com.tw, kimpo30107@yahoo.com.tw).

Jhen-Ni Ye is with the Graduate Institute of Technological \& Vocational Education, National Taipei University of Technology, Taiwan (corresponding author; e-mail: jhen13211321@gmail.com). place it at the center part of educational activities [3] However, in many European countries, the enrollment rate of STEM degrees is still low, and related research suggests that this may be mainly due to teaching problems, such as the lack of hands-on activities in science and mathematics education suitable for secondary education [4].

Therefore, influenced by the "STEM to STEAM" movement, the inclusion of Arts has become a new wave of STEAM education [1], and related STEAM activities are still in full swing. Educational robot competitions for school-age students are increasingly popular around the world [5], and the way Maker Education integrates with STEAM education allows learners to learn by using engineering ideas and models [6]. The STEAM process involves developing innovative knowledge, so students will find new ways to explain scientific phenomena, make predictions, solve problems, and express results in certain situations [7]. The STEAM contest based on hands-on is used to cultivate learners' hands-on and STEAM skills, and the STEAM-related competitions could also enhance participants' communication, teamwork and personal skills development [8]. Therefore, STEAM's educational aims are to shape new knowledge through innovative methods, creativity, critical thinking, effective communication, teamwork, and more [9].

From the above, STEAM education is a form of learning based on the concept of teamwork, which aims to provide students with a comprehensive and meaningful learning experience [2]. The application of cooperative learning methods is believed to help strengthen the huge potential of learners integrating STEM or STEAM applications [10]. When learners engage in creative tasks, they can encourage them to communicate meaningfully and inspire them to explore [11]. Past research has shown that in the early stages of the innovation process, the positive behavior of team members is helpful for outcomes [12]. Thus, cooperative learning has proven to be one of the most successful teaching methods in secondary education [13]. Therefore, this study believes that the participation of creative tasks in STEAM contests based on teamwork will help bring a meaningful learning process to learners.

According to previous research on fairness and social justice, public awareness of the disadvantages of students in remote rural environments and remote areas has gradually increased [14], [15]. Also, related research further found that compared with students in other urban areas, students in rural areas are less interested in learning science [16]. However, as many as $33 \%$ of primary and secondary schools in Taiwan 
are rural schools [17], it is important to eliminate the gap between urban and rural students' interest in teaching and education, and to promote exchanges between the two sides. From the perspective of educational equity, science education in the rural areas must make new attempts in teaching methods. Relevant research points out that meaningful learning is not just based on the spread of teachers. It promotes the construction of knowledge through learners' experiences, feelings and exchanges with other learners. This educational perspective is based on constructivist learning methods and cooperative learning methods [18]. Therefore, letting urban and rural learners conduct cooperative-oriented STEAM learning should strengthen the STEAM learning effect of urban and rural students and bring them a meaningful learning experience.

Social interdependence theory (SIT) is widely used to explain cooperative learning. From the perspective of SIT, positive social interdependence is a set of rules, norms, or practices that promotes the actions of each member of the team and can help achieve common goals [19]. Research has shown that when cooperation becomes the norm, there is a cooperative attitude within the team [20]. In addition, some studies have pointed out that one of the necessary conditions for a successful learning environment is the student's attitude towards group cooperative learning [21]. On the other side, attitudes assessed by students may provide new insights to understand how attitudes may hinder or promote learning [22]. Also, research shows that a good cooperative attitude will naturally stimulate the initiative of team members [23]. Therefore, this study uses SIT to explore the relationship between participants' cooperative attitude and creative task engagement in the STEAM contest.

In addition, expectancy-value theory (EVT) is widely used to explain learner behavior-value relationships. EVT is an educational theory that explains students' perseverance [24]. From the perspective of EVT, attitude beliefs associate objects with certain attributes or outcomes [25], and the expectancy-value model has been widely used as a conceptual framework to explain the incentive process [26]. Therefore, this study uses the motivational view of expectancy-value theory [24] to explain why learners make choices and why they insist on an activity motive, thereby exploring what the relationship between creative task engagement and competition value.

In summary, the STEAM co-creation contest based on cooperative learning between urban and rural students is a meaningful learning activity. Understanding the attitude-behavior-value patterns perceived by participants has meaning. However, relevant research is still a minority. Therefore, on the basis of SIT and EVT, this study explored the relationship between cooperative attitude, creative task engagement and competition value.

\section{LITERATURE REVIEW}

\section{A. Urban and Rural Students' STEAM Co-creation Contest}

The PowerTech Youth Science and Technology Creation
Contest that it aims to improve participants' STEAM learning and problem solving skills is organized by the Taiwan Creative Development Association and the National Taiwan Normal University. In the contest, participants need to complete a group of mechanical beasts at the contest site to play in a day [27], which means live production in the morning and competition in the afternoon (Relay competitions, tug-of-war competitions, art modeling judging). In the production process, the team must carry out the structural design and production of the mechanical beast according to the designated production theme, and the participants must cooperate to complete the work without the help of parents or teachers or to avoid the influence of external interference [28]. The STEAM co-creation contest for urban and rural students is based on PowerTech's activities and can be regarded as a creative task. The contest is based on assisting the development of curriculum and teaching plans for primary and secondary schools in urban and rural areas, and brings the spirit of hands-on "STEAM" -science, technology, engineering, art, mathematics into urban and rural schools. Among them, the primary school team has 5-6 students per team and the junior high school team has 3-4 students, and the participating teams in these two categories must include students from urban areas and rural areas [29], as shown in Fig. 1-3.

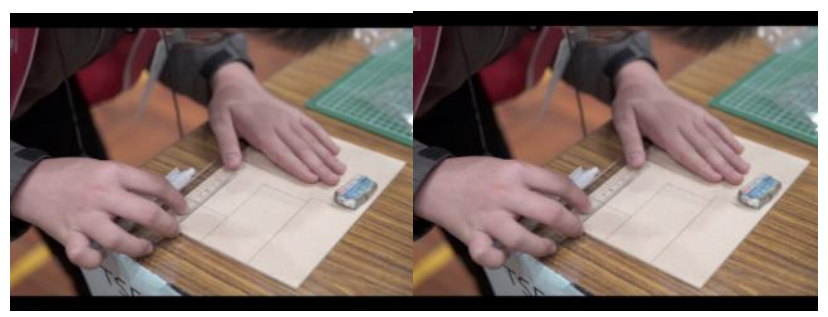

Fig. 1. The production process of the contestants.

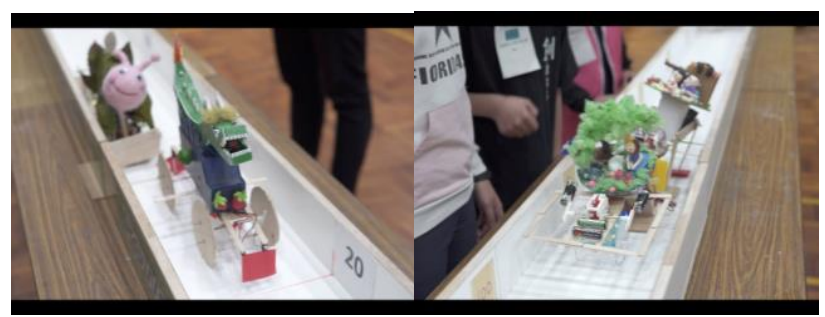

Fig. 2. Mechanical beast relay competition.

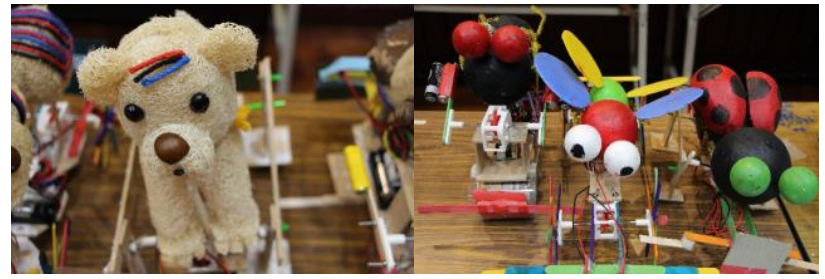

Fig. 3. Mechanical beast works.

\section{B. Cooperative Attitude}

Attitude refers to how well a person evaluates the behavior in question [30], and also refers to a person's positive or negative perception of a specific behavior [31]. Therefore, attitudes are widely described and analyzed as cognition, emotions, and habits [32], and play a vital role in our daily decision-makings [33].

In the course of cooperation-based learning, participants 
achieve their goals through cooperation among all members participating in group activities [34]. Therefore, understanding the learner's attitude towards cooperative learning will help the implementation of teaching. Cooperative learning attitude could be defined as the expression of opinions about relevant extroverted behaviors and introverted feelings when students participate in groups or teams [21].

Moreover, a writing teaching study on cooperative learning points out that cooperative attitudes are derived from the positive or negative evaluation views of learners on cooperative writing activities, so understanding how learners' attitudes towards cooperative writing is extremely important [35]. That is why this study used a cooperative attitude to explore participants' perception of teamwork in the STEAM co-creation contest between urban and rural students.

\section{Creative Task Engagement}

The daily meaning of engagement refers to participation, commitment, enthusiasm, concentration, dedicated effort, dedication, and vitality [36], [37], if the learner does not invest enough in the learning task, there will be no meaningful learning [38]. Therefore, engagement is regarded as a key factor for learning success [39]. Fredricks, Blumenfeld and Paris (2004) distinguish engagement into three types, behavioral engagement, emotional engagement and cognitive engagement. Behavioral engagement refers to effort, participation, attendance, and other task behaviors [40], while emotional engagement refers to the emotional performance (such as interest) of students in the school, and cognitive engagement refers to the focus on the task, the deep thinking process or the application of self-regulated meta-cognitive strategies [41], [42]. Based on this, this study used creative task engagement to explore participants' perceptions of behavioral, emotional, and cognitive engagement when participating in creative tasks in the STEAM co-creation contest between urban and rural students.

\section{Competition Value}

Value is an abstract concept, and its meaning will vary according to the topic of discussion [43]. Value is a variable based on expectancy-value theory (EVT) and is defined as how the task meets the needs of students [44]. Therefore, the utility value that brings learners usefulness is highly valued in science education [41]. Utility value refers to the perceived usefulness of a task or activity for a person's future plans [45], [46]. If students encounter topics or tasks that seem to be of no help to individuals, they may become uninteresting [47], that is, when the task activity does not have utility value, it will not be able to inspire participants to engage in the activity. The study believes that one way to get participants interested in activities is to find meaning and value in these activities [48]. Moreover, relevant studies indicate that utility value is related to positive learning outcomes in science [41]. Thus, this study explored participants' perception of competition value in the STEAM co-creation contest between urban and rural students in terms of utility value.

\section{RESEARCH HYPOTHESES}

\section{A. Relationship between Cooperative Attitude and Creative Task Engagements}

When students engage in a collaborative learning environment, they most often demonstrate learning engagement behavior through speech, eye contact, gestures, and posture [49]. Research indicates that learners' engagement behaviors are generated through good attitudes, and this view can be used to explain individual behaviors [50]. Studies have shown that when students believe that they have similar goals as their team and actively rely on the actions of the group, the results of cooperation are most effective. This positive interdependence is believed to promote cooperative interaction [51]. Students' attitudes will be related to the results of their cooperative learning activities [34]. When students have a close cooperative relationship with their peers in their learning activities, their engagement behavior will be better [39]. At the same time, related research has confirmed that learning with peers can not only improve the overall performance of the learner, but also benefit the peers. Improving the quality of the team's work through peer cooperation will indirectly improve the team's performance [52]. The method based on cooperative learning is regarded as a method that can increase learning investment and bring meaningful learning to learners [53]. Therefore, those with higher cooperation attitudes may have better creative task engagement. Therefore, this study intended to explore the relationship between participants' cooperation attitude and creative task engagement in this urban-rural student STEAM co-creation contest. The hypotheses were as follows:

Hypothesis 1: Cooperation attitude and behavioral engagement is positively correlated.

Hypothesis 2: Cooperation attitude and emotional engagement is positively correlated.

Hypothesis 3: Cooperation attitude and cognitive engagement is positively correlated.

\section{B. The Relationship between Creative Task Engagement and Competition Value}

Learning engagement has been conceptualized as students participating in educational activities in terms of time and energy [54]. If we think that this activity is not an important task, and that the activity cannot learn important skills, then learners will not be interested in completing this activity [55]. Some studies indicate that learning engagement is a powerful support for students' psychological, social development and learning success [56]. Moreover, related research has always been associated with positive learning outcomes, such as learning achievements, knowledge growth, etc. [57]. Thus, engagement is understood as an indispensable behavior for learning, and the relationship between input behavior and academic performance has also been repeatedly confirmed through empirical research [58]. Historically, student engagement has been focused on improving achievement [59], so when learners engage in learning activities, they can build their knowledge [60]. Studies have clearly pointed out that only when students participate in academic activities in a hands-on manner will they acquire knowledge and skills, but 
they must actively engage in learning tasks, otherwise they will not learn effectively or obtain excellent learning achievements [37]. Therefore, as participants become more involved in competitions with creative tasks, they will likely experience higher levels of competition value. Therefore, this study intends to explore the participants' hypotheses about the relationship between creative task engagement and competition value in this urban-rural student STEAM co-creation contest, as follows:

Hypothesis 4: Behavioral engagement is positively correlated with competition value.

Hypothesis 5: Emotional engagement is positively correlated with competition value.

Hypothesis 6: Cognitive engagement is positively correlated with competition value.

\section{RESEARCH DESIGN}

\section{A. Research Framework}

The application of social interdependence theory (SIT) in education has become one of the most successful and extensive applications in educational psychology. Positive interdependence is considered to promote interaction, while negative interdependence is considered to cause confrontation or bad interaction [61]. In addition, expectancy-value theory (EVT) states that students'choices, behaviors, and perseverance can be explained by their ability beliefs, task-specific expectations, and subjective task values [62]. Based on SIT and EVT, this study aggregated relevant literature on cooperation attitude, creative task engagements and competition value, proposed six research hypotheses, and constructed the following research model, as shown in Fig. 4.

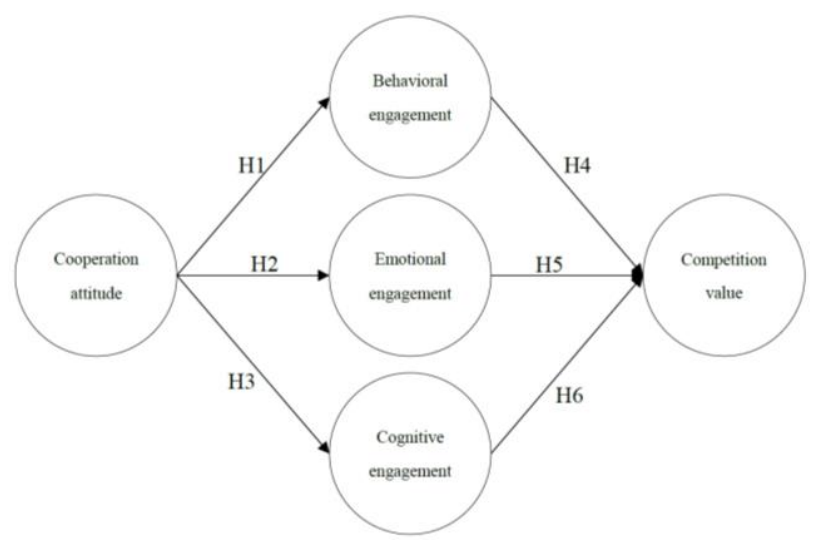

Fig. 4. Research framework.

\section{B. Procedure}

This study adopted purposive sampling method, and its participants were the students of the elementary school group and junior high school group who participated in the 2019 STEAM co-creation contest for urban and rural students held on March 16, 2019. The questionnaires were distributed, and unless the questionnaires had a research statement and guidance, indicating that the questionnaires were filled were deemed to be willing to participate in this research. During the contest, the host also filled in the oral guidance at the event site, and were not willing to participants who assist in filling out the questionnaires will not affect the selection results, and the questionnaire data will be filled in and recovered anonymously.

\section{Participants}

Participants in this study were 188 , the effective sample number was 163 , and the effective recovery rate was $86.7 \%$, including 114 boys (69.9\%), 49 girls (30.1\%), and 107 elementary school students $(65.6 \%), 56$ junior high school students (34.4\%); 58 urban school students (35.6\%), rural school students $105(64.4 \%)$, the average age was 11.83 years old, the standard deviation was 1.26 years old.

\section{Questionnaires}

This study collected data through a questionnaire survey. The questionnaire content was translated and revised by the scale of the previous study, and the validity was reviewed by two education experts. The questionnaire content used the Likert 5-point scale ( 1 to 5 indicates strong disagreement to strong agreement) as the evaluation standard. After the questionnaires were recovered, first-order confirmatory analysis was conducted with AMOS 20.0, and then reliability and validity analyses were performed using SPSS 23 .

\section{1) Cooperative attitude}

Attitude refers to how well one evaluates the behavior in question [30], and based on this concept, this study revised the cooperative attitude of Hong, Ye, Ho, and Lin (in press) scale [63], with a total of 10 questions, to measure participants' perception of cooperation attitudes of team participation in the STEAM co-creation contest, e.g. I will respond immediately when a partner asks for help.

\section{2) Creative task engagement}

Fredrick et al. (2004) distinguished engagement into three types: behavioral engagement, emotional engagement, and cognitive engagement [40], and this study was based on this classification. Furthermore, this study edited the learning engagement scale of Hong, Chen, Ye and Chen (2020) [64], in which behavioral engagement was 8 questions, emotional engagement was 9 questions, and cognitive engagement was 8 questions to measure the degree of participation of participants in creative tasks in the STEAM co-creation contest. e.g. I usually go to the classroom on time when I want to practice; I am happy to help the team members; I will plan in advance before making a mechanical beast.

\section{3) Competition value}

Utility value refers to the perceived usefulness of a task or activity for an individual's future plans [45], [46]. Based on this concept, this study edited the game value scale of Hwang, Hong, Ye, Wu, Tai and Kiu (2019) [65], a total of 6 questions to measure the value perception of participants in the STEAM co-creation contest, e. g. I think the creation of mechanical beasts created by urban and rural areas can increase the understanding of scientific knowledge.

\section{SURVEY InSTRUMENTS}

\section{A. Item Analyses}

The analysis instrument used in this research project is the 
first-order confirmatory factor analysis (CFA). According to the indicators proposed by Hair, Black, Babin and Anderson (2010), Kenny, Kaniskan and McCoach (2015), the following recommendations were as follows: $\chi^{2} / d f$ value should not be higher than 5, and the Root Mean Square Error of Approximation (RMSEA) should not be higher than 0.1, both the Goodness-of-fit index (GFI) and the Adjusted Goodness-of-fit index (AGFI) should not be less than 0.8, and the factor loading (FL) should not be less than 0.5 [66], [67]. The result of deleting the questions was the cooperative attitude from 10 to 7 questions, behavioral engagement from 8 to 4 questions, emotional engagement from 9 to 5 questions, cognitive engagement from 8 to 5 questions, and competition value from 6 to 4 questions.

The external validity of this study is used to measure the interpretation range of the construct items [68]. When the $t$ value of the item is higher than $3(* * * p<.001)$, it represents the item had external validity. Table II shows that the $t$ value was higher than $11.058(* * * p<0.001)$, which showed that all items in this study had external validity [69].

\begin{tabular}{ccccccc}
\multicolumn{7}{c}{ TABLE I: FIRST-ORDER CONFIRMATORY ANALYSIS } \\
\hline \hline Index & $\chi^{2}$ & df. & $\chi^{2} /$ df. & RMSEA & GFI & AGFI \\
\hline $\begin{array}{c}\text { Threshold } \\
\text { Cooperative } \\
\text { attitude }\end{array}$ & 14.6 & 14 & 1.043 & .016 & .975 & .950 \\
$\begin{array}{c}\text { Behavioral } \\
\text { engagement } \\
\text { Emotional } \\
\text { engagement } \\
\text { Cognitive } \\
\text { engagement }\end{array}$ & 2.9 & 2 & 1.45 & .051 & .991 & .955 \\
$\begin{array}{c}\text { Competition } \\
\text { value }\end{array}$ & 2.6 & 5 & 1.32 & .045 & .984 & .953 \\
\hline \hline
\end{tabular}

\section{B. Reliability and Validity Analyses}

\section{1) Reliability analyses}

Javali, Gudaganavar, and Jain (2011) Cronbach's $\alpha$ should not be less than 0.7 [70], and after Cronbach's $\alpha$ passes the recommended value, the CR value is retested, while Hair et al. (2010) suggest that the CR value should not be less than .70 [66], and the Cronbach's $\alpha$ value in this study is between .805 and .886 , and the CR value is between .844 and .886 , which meets the recommended standard, as shown in Table II.

\section{2) Convergence validity analyses}

Hair et al. (2010) suggested that the factor loading (FL) value should not be less than .50 [66], and the FL value of the cooperative attitude in this study ranged from .690 to .793 . Behavioral engagement ranged from .735 to .886 , emotional engagement ranged from .679 to .824 , cognitive engagement ranged from .690 to .807 , and competition values ranged from .683 to .747 , such as shown in Table II Hair, Ringle, and Sarstedt (2011) recommend that the average variance extracted (AVE) value should not be less than 0.5 , indicating that the construct had convergence validity [71], while the AVE value in this study between .521 and .631 , as shown in Table II.

\section{3) Discrimination validity analyses}

Gefen, Straub, \& Boudreau (2000) pointed out that the square root of the AVE value of each construct must be higher than the Pearson correlation coefficient value of the other constructs, indicating that the construct has discrimination validity [72]. The analysis results of this study show that each construct in this study has different validity, as shown in Table III.

TABLE II: ITEM ANALYSIS OF RELIABILITY AND VALIDITY

\begin{tabular}{cccccc}
\hline \hline Index & $M$ & $S D$ & $\alpha$ & CR & AVE \\
\hline Threshold & --- & --- & $>.7$ & $>.7$ & $>.5$ \\
Cooperative attitude & 4.324 & 596 & .886 & .886 & .526 \\
Behavioral engagement & 4.230 & 636 & .871 & .872 & .631 \\
Emotional engagement & 4.150 & .573 & .858 & .859 & .550 \\
& & & & & \\
Cognitive engagement & 4.217 & .555 & .827 & .844 & .521 \\
Competition & 4.179 & .647 & .886 & .886 & .526 \\
value & & & & & \\
\hline \hline
\end{tabular}

TABLE III: CONSTRUCT DISCRIMINATIVE VALIDITY ANALYSIS

\begin{tabular}{cccccc}
\hline \hline Constructs & 1 & 2 & 3 & 4 & 5 \\
\hline $\begin{array}{c}\text { 1. Cooperative } \\
\text { attitude }\end{array}$ & $\mathbf{( . 7 2 5 )}$ & & & & \\
$\begin{array}{l}\text { 2. Behavioral } \\
\text { engagement }\end{array}$ & .308 & $\mathbf{( . 7 9 4 )}$ & & & \\
$\begin{array}{l}\text { 3. Emotional } \\
\text { engagement }\end{array}$ & .289 & .546 & $\mathbf{( . 7 4 2 )}$ & & \\
$\begin{array}{l}\text { 4. Cognitive } \\
\text { engagement }\end{array}$ & .295 & .552 & .548 & $\mathbf{( . 7 2 2 )}$ & \\
5. Competition value & .160 & .524 & .511 & .492 & $\mathbf{( . 7 2 9 )}$ \\
\hline \hline
\end{tabular}

\section{RESULTS}

\section{A. Overall Fit Analyses}

Hair et al. (2010) suggested that the recommended value of each fitting index should be chi-square degrees of freedom ratio $\left(\chi^{2} / d f\right)$ should not be higher than 5 [66]. Abedi, Rostami, and Nadi (2015) suggested the root mean square error approximation (RMSEA) should not be higher than .1, while goodness of fit index (GFI), adjusted goodness of fit index (AGFI), Normed fit index (NFI), Non normed fit index (NNFI), Comparative fit index (CFI), Incremental fit index (IFI) and Relative fit index (RFI) should not be less than .80 [73]. Hair et al. (2010) also suggested that the Parsimonious normed fit index (PNFI) and the Parsimonious goodness of fit index (PGFI ) should not be less than 0.5 [66]. The fitted index values for this study were $\chi^{2}=419.7, d f=269, \chi^{2} / d f=$ $1.560, \mathrm{RMSEA}=.059, \mathrm{GFI}=.837, \mathrm{AGFI}=.806, \mathrm{NFI}=.828$, $\mathrm{NNFI}=.911, \mathrm{CFI}=.920, \mathrm{IFI}=.921, \mathrm{RFI}=.805, \mathrm{PNFI}=.724$, PGFI $=.682$, the values of each fit index are in line with the scholars' recommended standards, and have good model adaptability.

\section{B. Research Model Verification}

The results of model verification show that cooperation attitude and behavioral engagement are positively correlated $\left(\beta=.387^{* * *}, t=4.241\right)$, cooperation attitude and emotional engagement are positively correlated $(\beta=.362 * * *, t=4.013)$, cooperation attitude is positively correlated with cognitive engagement $(\beta=.380 * * *, t=3.961)$, behavioral engagement is positively correlated with competition value $\left(\beta=.289^{* *}, t\right.$ $=3.693)$, emotional engagement is positively correlated with competition value $\left(\beta=.385^{* * *}, t=3.499\right)$, cognitive engagement and competition value showed a positive correlation $\left(\beta=.309^{* *}, t=2.696\right)$, as shown in Fig. 5.

The explanatory power of cooperative attitude to behavioral engagement is $15 \%, f^{2}$ is .196 ; the explanatory 
power of cooperative attitude to emotional engagement is $13.1 \%, f^{2}$ is .151 ; the explanatory power of cooperative attitude to cognitive engagement is $14.5 \%, f^{2}$ is .170; and the explanatory power of the three types of competitive engagement to the competition value is $41.8 \%$, and $f^{2}$ is .718 .

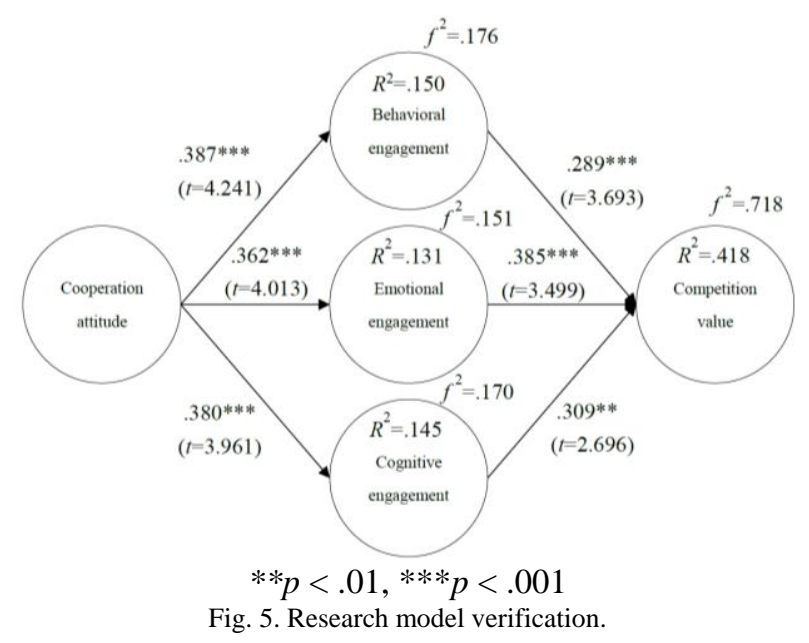

\section{Indirect Effect Analysis}

The indirect effect analysis results show that the cooperative attitude has an indirect positive correlation with the competition value $(\beta=.371 * * *)$, as shown in Table IV.

TABLE IV: INDIRECT EFFECT ANALYSIS

\begin{tabular}{ccc}
\hline \hline Construct & \multicolumn{2}{c}{ Cooperative attitude } \\
\hline Competition value & $.371^{* * *}$ & $\mathrm{CI}$ \\
\hline \hline
\end{tabular}

\section{DISCUSSION}

Cooperative attitude is the positive or negative evaluation opinion of learners on team cooperation activities [35]. The research results show that the participants in this study have a high level of cooperation attitude $(M=4.324, S D=.596)$. Behavioral engagement refers to effort, participation, attendance, and other learning behaviors, emotional engagement refers to the students' emotional performance, such as interest, cognitive engagement refers to the application of learning cognitive focus, deep thinking process or self-regulated meta-cognitive strategies [41], [42]. The research results also show that the participants in this study have good behavioral engagement $(M=4.230, S D$ $=.636)$, emotional engagement $(M=4.150, S D=.573)$, and cognitive engagement $(M=4.217, S D=.555)$. The utility value refers to the perceived usefulness of the task or activity for the learner's future plans [45], [46]. The research results show that the participants have a high degree of competition value for this STEAM co-creation contest $(M=4.179, S D$ $=.647)$.

\section{A. Cooperation Attitude Is Positively Correlated with Creative Task Engagement}

Heflin et al. (2017) stated that when students engage in a cooperative learning environment, they most often demonstrate learning engagement behavior through speech, eye contact, gestures and postures [49]. The Sahoo and Pillai (2017) study pointed out that learners' engagement behaviors are generated through good attitudes, and this view can be used to explain individual behaviors [50]. Herrmann's (2013) research also suggests that when students believe that they have similar goals as their team and are actively dependent on the actions of the group, the cooperative outcome is most effective. This positive interdependence is believed to promote cooperative interaction [51]. Herrmann's (2013) research also suggests that when students believe that they have similar goals as their team and are actively dependent on the actions of the group, the cooperative outcome is most effective. This positive interdependence is believed to promote cooperative interaction [51]. It can be found that the attitude of students is related to the results of their cooperative learning activities [34]. Fredricks et al. (2016) believe that when students have a close cooperative relationship with their peers in learning activities, they will be more engaged in behavior [39]. At the same time, the research by Liaw et al. (2008) confirmed that learning with peers not only improves the learner's overall performance, but also benefits the peers. Therefore, peer collaboration can improve the quality of the team 's work and thereby improve team performance [52]. Fothermore, Smith et al. (2005) stated that the method based on cooperative learning can be regarded as a method to increase learning engagement and can bring meaningful learning to learners [53]. It can be seen from the above that a good cooperative attitude will help participants to invest more in STEAM co-creation contest activities. The research results show that the cooperative attitude is positively correlated with three types of creative task engagement, such as behavioral engagement, emotional engagement and cognitive engagement, which coincides with relevant research opinions.

\section{B. Creative Task Engagement Is Positively Correlated with Competition Value}

Kuh (2009) conceptualized learning engagement as students participating in educational activities in terms of time and energy [54]. However, Kale (2018) stated that if we think that this activity is not an important task, and that the activity cannot learn to be important skills, then learners are not interested in completing this activity [55]. Therefore, Junco et al. (2011) pointed out that learning engagement is a powerful support for students' psychological, social development and learning success [56]. Furthermore, Vollet et al. (2017) research confirmed that learning engagement and positive learning results, such as learning achievement, knowledge growth, etc. are related [57]. So engagement is understood as an indispensable behavior for learning, and the relationship between engagement behavior and academic performance has also been repeatedly confirmed through empirical research [58]. Historically, student engagement has been focused on improving achievement [59]. Therefore, Dahalan et al. (2012) stated that when learners engage in learning activities, they can build their own knowledge [60]. The Skinner and Pitzer (2012) study clearly pointed out that only when students participate in academic activities in a hands-on manner will they acquire knowledge and skills, but they must actively engage in learning tasks, otherwise they will not learn effectively or achieve excellent learning achievements [37]. In summary, when participants deeply 
invest in STEM co-creation contest activities, they will feel a higher level of competition value perception. The research results show that three types of creative task engagement, including behavioral engagement, emotional engagement and cognitive engagement are positively correlated with the value of the competition, which is consistent with previous research arguments.

\section{CONCLUSION}

Meaningful learning must include a social, cooperative, purposeful, real and active learning process [74]. The study found that in the STEAM-based co-creation contest, participants have good Creative task engagement behavior $(M>4)$, it can be seen that this competition brings a meaningful learning process to learners. In addition, the research indicates that teamwork learning contributes to meaningful learning and the construction of new knowledge [75]. There have been many empirical studies of cooperative learning in the past, confirming the positive benefits of cooperative learning. However, the discussion of cooperation attitudes is still rare, therefore, based on the theory of social interdependence and expected value theory, this study explores the relationship between cooperative attitude, creative task engagement and competition value. The verification results show that cooperative attitude and three types of creative task engagement, such as behavioral engagement, emotional engagement and cognitive engagement, showed a positive correlation. Three types of creative task engagements are also positively related to the value of the competition.

In addition, many educational psychology researches are very interested in the factors that affect learners' learning-related behaviors [76]. In this study, it was found that when participants have a high degree of cooperative attitude, in competition activities, the better the engagement behavior. Therefore, in activities based on cooperative learning, it is important to assess the cooperative attitude of participants.

\section{A. Implication}

Research indicates that it is important to understand how learners' cooperative attitudes affect their learning [35]. The research results show that a good cooperative attitude is beneficial to the growth of learners' three types of creative task emgagement, including behavioral emgagement, emotional emgagement and cognitive emgagement. Therefore, this study suggests that the instructors of the participating teams should first help participants to establish a good cooperative attitude in the guidance process, which will help participants to obtain a better learning experience in the contest.

In addition, research indicates that broad participation of learners in the STEM field is an important part of expanding innovation and an important social justice issue [77], so good STEAM activities are regarded as a social practice. Social practice theory (SPT) refers to off-campus cooperation, disciplinary integration, and interdisciplinary [78]. Accordingly, the STEAM co-creation contest between urban and rural students conforms to the concept of SPT.

\section{B. Limitation and Further Study}

This study is a confirmatory study, so the research results are only suitable to explain the players participating in the STEAM co-creation contest for urban and rural students. Although the analysis results show that a good cooperative attitude helps increase learners' creative task engagement, the level of creative task engagement can also obtain good competition value, but it is not necessarily suitable for inference to other types of STEAM contest. Therefore, in the future, the tools and models of this research can be applied to participants in different STEAM contests to verify whether the cooperative attitudes are different in the correlation between the three types of creative task engagement constructs, such as behavioral engagement, emotional engagement and cognitive engagement.

Previous studies have pointed out that the number of women participating in STEM learning is significantly less than that of men, and the interest in STEM is also low [79]. However, this study is a confirmatory study, and the gender ratio with male and female participants has a large gap, but the difference cannot be compared. Therefore, it is recommended that the follow-up study can increase the sample size of female participants and balance the two gender ratios to conduct a comparative study of difference analysis.

\section{CONFLICT OF INTEREST}

The authors declare no conflict of interest.

\section{INTEREST AND AUTHOR CONTRIBUTION}

First author conducted the research; second and third author analyzed the data; all authors wrote the paper; all authors had approved the final version.

\section{ACKNOWLEDGEMENT}

This work was financially supported by the "Institute for Research Excellence in Learning Sciences" of National Taiwan Normal University (NTNU) from The Featured Areas Research Center Program within the framework of the Higher Education Sprout Project by the Ministry of Education (MOE) in Taiwan.

\section{REFERENCES}

[1] W. L. Tang, "Explore the development of STEM and STEAM education in the USA," Curriculum \& Instruction Quarterly, vol. 22, no. 2, pp. 49-77, 2019.

[2] A. Gomez and B. Albrecht, "True STEM education," Technology and Engineering Teacher, vol. 73, no. 4, pp. 8-16, 2013.

[3] H. Yamagata and T. Morita, "Design of contest for educational underwater robot for STEM: Learning applying modeling based on control engineering," Journal of Robotics and Mechatronics, vol. 29, no. 6 , pp. $957-968,2017$

[4] A. P. Achilleos et al., "SciChallenge: A social media aware platform for contest-based STEM education and motivation of young students," IEEE Transactions on Learning Technologies, vol. 12, no. 1, pp. 98-111, 2018.

[5] A. Eguchi, "RoboCupJunior for promoting STEM education, 21st century skills, and technological advancement through robotics competition," Robotics and Autonomous Systems, vol. 75, pp. 692-699, 2016.

[6] Q. Fu and C. Wang, "When maker in STEAM education," Modern Educational Technology, vol. 24, no. 10, pp. 37-42, 2014. 
[7] G. Ozkan and U. U. Topsakal, "Exploring the effectiveness of STEAM design processes on middle school students' creativity," International Journal of Technology and Design Education.

[8] E. Sklar, A. Eguchi, and Johnson, "Scientific challenge award: RoboCupJunior-learning with educational robotics," AI Magazine, vol. 24 , no. 2 , pp. 43-46, 2003.

[9] C. F. Quigley and D. Herro, "Finding the joy in the unknown": Implementation of STEAM teaching practices in middle school science and math classrooms, Journal of Science Education and Technology, vol. 25 , no. 3 , pp. $410-426,2016$

[10] T. J. M. K. A. Smith, "Advancing the state of the art of STEM integration," Journal of STEM Education, vol. 15, no. 1, pp. 5-10, 2014.

[11] H. C. Wang, "The influence of creative task engagement on English L2 learners' negotiation of meaning in oral communication tasks," System, vol. 80, pp. 83-94, 2019.

[12] M. C. Caniëls, "Proactivity and supervisor support in creative process engagement," European Management Journal, vol. 37, no. 2, pp. 188-197, 2019.

[13] D. W. Johnson, R. T. Johnson, and K. Smith, "The state of cooperative learning in postsecondary and professional settings," Educational Psychology Review, vol. 19, no. 1, pp. 15-29, 2007.

[14] B. Atweh, C. Vale, and M. Walshaw, "Equity, diversity, social justice and ethics in mathematics education," Research in Mathematics Education in Australasia 2008-2011, Leiden, NL: Brill Sense, 2012, pp. 39-65.

[15] C. Vale, B. Atweh, R. Averill, and A. Skourdoumbis, "Equity, social justice and ethics in mathematics education," Research in Mathematics Education in Australasia 2012-2015, Singapore, SG: Springer, 2016, pp. $97-118$.

[16] T. Lyons and F. Quinn, "Rural high school students' attitudes towards school science," Australian and International Journal of Rural Education, vol. 22, no. 2, pp. 21-28, 2012.

[17] J. C. Chan and P.-C. Wu, "The innovative development of rural education," Journal of Education Research, vol. 258, pp. 28-41, 2015.

[18] Y. Sharan, "Meaningful learning in the cooperative classroom," Education 3-13, vol. 43, no. 1, pp. 83-94, 2015.

[19] F. Butera and C. Buchs, "Social interdependence and the promotion of cooperative learning," Social Psychology in Action, Cham, $\mathrm{CH}$ Springer, 2019, pp. 111-127.

[20] D. J. Hall, J. B. Skipper, B. T. Hazen, and J. B. Hanna, "Inter-organizational IT use, cooperative attitude, and inter-organizational collaboration as antecedents to contingency planning effectiveness," The International Journal of Logistics Management, vol. 23, no. 1, pp. 50-76, 2012.

[21] Ö. Korkmaz, "A validity and reliability study of the online cooperative learning attitude scale (OCLAS)," Computers \& Education, vol. 59, no. 4, pp. 1162-1169, 2012.

[22] N. Farzaneh and D. Nejadansari, "Students' attitude towards using cooperative learning for teaching reading comprehension," Theory and Practice in Language Studies, vol. 4, no. 2, pp. 287-292, 2014.

[23] S. Er and B. A. Ataç, "The attitudes of students towards cooperative learning in ELT classes," International Online Journal of Education and Teaching, vol. 1, no. 2, pp. 109-122, 2014.

[24] J. Eccles et al., "Expectancies, values, and academic behaviors," Achievement and Achievement Motivation, San Francisco, CA: W. H. Freeman, 1983, pp. 75-146.

[25] X. H. Zhang et al., "Applying the expectancy-value model to understand health values," Value in Health, vol. 11, pp. S61-S68, 2008.

[26] I. Plante, P. A. O'Keefe, and M. Théorêt, "The relation between achievement goal and expectancy-value theories in predicting achievement-related outcomes: A test of four theoretical conceptions," Motivation and Emotion, vol. 37, no. 1, pp. 65-78, 2013

[27] J. C. Hong, C. H. Chang, C. R. Tsai, and K. H. Tai, "How situational interest affects individual interest in a STEAM competition," International Journal of Science Education, vol. 41, no. 12, pp. 1667-1681, 2019.

[28] J. C. Hong, C. L. Lin, and Y. L. Lin, "Operating a successful PowerTech creativity contest," Journal of Technology Studies, vol. 33 , no. 1 , pp. $25-31,2007$.

[29] National Taiwan Normal University. (2019). 2019 urban and rural students STEAM-self-made co-creation competition rules. [Online] Available: https://apps.nknush.kh.edu.tw/ZeroBB/Download?upfileid=26618

[30] M. Fishbein and I. Ajzen, Belief, Attitude, Intention, and Behavior: An Introduction to Theory and Research, Boston, MA: Addison-Wesley, 1975.
[31] P. Ifinedo, "Examining students' intention to continue using blogs for learning: Perspectives from technology acceptance, motivational, and social-cognitive frameworks," Computers in Human Behavior, vol. 72 , pp. 189-199, 2017

[32] Y. H. Kim, D. J. Kim, and K. Wachter, "A study of mobile user engagement (MoEN): Engagement motivations, perceived value, satisfaction, and continued engagement intention," Decision Support Systems, vol. 56, pp. 361-370, 2013.

[33] R. Gwinn and I. Krajbich, "Attitudes and attention," Journal of Experimental Social Psychology, vol. 86, p. 103892, 2020.

[34] C. W. Nam and R. D. Zellner, "The relative effects of positive interdependence and group processing on student achievement and attitude in online cooperative learning," Computers \& Education, vol. 56, no. 3, pp. 680-688, 2011.

[35] W. Chen and S. Yu, "A longitudinal case study of changes in students' attitudes, participation, and learning in collaborative writing," System, vol. 82, pp. 83-96, 2019.

[36] W. B. Schaufeli, "What is engagement?" Employee Engagement in Theory and Practice, Abingdon-on-Thames, UK: Routledge, 2013, pp. 29-49.

[37] E. A. Skinner and J. R. Pitzer, "Developmental dynamics of student engagement, coping, and everyday resilience," Handbook of Research on Student Engagement, Boston, MA: Springer, 2012, pp. 21-44.

[38] M. Qian and K. R. Clark, "Game-based learning and 21st century skills: A review of recent research," Computers in Human Behavior, vol. 63, pp. $50-58,2016$

[39] J. A. Fredricks, M. Filsecker, and M. A. Lawson, "Student engagement, context, and adjustment: Addressing definitional, measurement, and methodological issues," Learning and Instruction, vol. 43, pp. 1-4, 2016.

[40] J. A. Fredricks, P. C. Blumenfeld, and A. H. Paris, "School engagement: Potential of the concept, state of the evidence," Review of Educational Research, vol. 74, no. 1, pp. 59-109, 2004.

[41] M. Bathgate and C. Schunn, "Factors that deepen or attenuate decline of science utility value during the middle school years," Contemporary Educational Psychology, vol. 49, pp. 215-225, 2017.

[42] D. J. Shernoff et al., "Student engagement as a function of environmental complexity in high school classrooms," Learning and Instruction, vol. 43, pp. 52-60, 2016.

[43] C. M. Chiu et al., "Usability, quality, value and e-learning continuance decisions," Computers \& Education, vol. 45, no. 4, pp. 399-416, 2005.

[44] A. Wigfield and J. S. Eccles, "The development of achievement task value: A theoretical analysis," Developmental Psychology, vol. 12, pp. 265-310, 1992

[45] M. Akcaoglu et al., "Outcomes from a self-generated utility value intervention on fifth and sixth-grade students' value and interest in science," International Journal of Educational Research, vol. 87, pp. 67-77, 2018.

[46] E. R. Brown et al., "From bench to bedside: A communal utility value intervention to enhance students' biomedical science motivation," Journal of Educational Psychology, vol. 107, no. 4, pp. 1116-1135, 2015.

[47] E. A. Canning et al., "Unintended consequences of framing a utility-value intervention in two-year colleges," Learning and Instruction, vol. 62, pp. 37-48, 2019.

[48] A. Durik and J. Harackiewicz, "Different strokes for different folks: How personal interest moderates the effects of situational factors on task interest," Journal of Educational Psychology, vol. 99, pp. 597-610, 2007.

[49] H. Heflin, J. Shewmaker, and J. Nguyen, "Impact of mobile technology on student attitudes, engagement, and learning," Computers \& Education, vol. 107, pp. 91-99, 2017.

[50] D. Sahoo and S. S. Pillai, "Role of mobile banking servicescape on customer attitude and engagement: An empirical investigation in India," International Journal of Bank Marketing, vol. 35, no. 7, pp. 1115-1132, 2017.

[51] K. J. Herrmann, "The impact of cooperative learning on student engagement: Results from an intervention," Active Learning in Higher Education, vol. 14, no. 3, pp. 175-187, 2013.

[52] S. S. Liaw, G. D. Chen, and H. M. Huang, "Users' attitudes toward Web-based collaborative learning systems for knowledge management," Computers \& Education, vol. 50, no. 3, pp. 950-961, 2008.

[53] K. A. Smith et al., "Pedagogies of engagement: Classroom-based practices," Journal of Engineering Education, vol. 94, no. 1, pp. $87-101,2005$ 
[54] G. D. Kuh, "What student affairs professionals need to know about student engagement," Journal of College Student Development, Vol. 50, pp. 683-706, 2009.

[55] U. Kale, "Technology valued? Observation and review activities to enhance future teachers' utility value toward technology integration," Computers \& Education, vol. 117, pp. 160-174, 2018.

[56] R. Junco, G. Heiberger, and E. Loken, "The effect of Twitter on college student engagement and grades," Journal of Computer Assisted Learning, vol. 27, no. 2, pp. 119-132, 2011.

[57] J. W. Vollet, T. A. Kindermann, and E. A. Skinner, "In peer matters, teachers matter: Peer group influences on students' engagement depend on teacher involvement," Journal of Educational Psychology, vol. 109, no. 5, pp. 635-652, 2017.

[58] J. D. Finn and K. S. Zimmer, "Student engagement: What is it? Why does it matter?" Handbook of Research on Student Engagement Boston, MA: Springer, 2012, pp. 97-131.

[59] J. Parsons and L. Taylor, "Improving student engagement," Current Issues in Education, vol. 14, no. 1, article number 745, 2011.

[60] N. Dahalan, H. Hassan, and H. Atan, "Student engagement in online learning: Learners attitude toward E-Mentoring," Procedia-Social and Behavioral Sciences, vol. 67, pp. 464-475, 2012.

[61] D. W. Johnson and R. T. Johnson, "An educational psychology success story: Social interdependence theory and cooperative learning," Educational Researcher, vol. 38, no. 5, pp. 365-379, 2009.

[62] F. Wu and W. Fan, "Academic procrastination in linking motivation and achievement-related behaviours: A perspective of expectancy-value theory," Educational Psychology, vol. 37, no. 6, pp. 695-711, 2017

[63] J. C. Hong et al., "The analysis of the relationship among science contestants' cooperation attitude, knowledge sharing and continuous sharing intention," Bulletin of Educational Psychology.

[64] J. C. Hong et al., "The relationship between adolescents' creative self-efficacy, competition engagements and the value of participating in competition - Taking the IEYI international exhibition for young inventors as an example," Bulletin of Educational Psychology, 2020.

[65] M. Y. Hwang et al., "Practicing abductive reasoning: The correlations between cognitive factors and learning effects," Computers \& Education, Vol. 138, pp. 33-45, 2019.

[66] J. F. Hair et al., Multivariate Data Analysis, 7th ed., Upper Saddle River, NJ: Pearson Prentice Hall, 2010.

[67] D. A. Kenny, B. Kaniskan, and D. B. McCoach, "The performance of RMSEA in models with small degrees of freedom," Sociological Methods \& Research, vol. 44, no. 3, pp. 486-507, 2015.

[68] M. K. Cor, "Trust me, it is valid: Research validity in pharmacy education research," Currents in Pharmacy Teaching and Learning, vol. 8, no. 3, pp. 391-400, 2016.

[69] S. B. Green and N. Salkind, Using SPSS for Windows and Macintosh: Analyzing and Understanding Data, 4th ed., Englewood Cliffs, NJ: Prentice-Hall, 2004.

[70] S. B. Javali, N. V. Gudaganavar, and S. M. Raj, "Effect of varying sample size in estimation of coefficients of internal consistency," Webmed Cent Biostat, vol. 2, no. 2, pp. 1-8, 2011.

[71] J. F. Hair, C. M. Ringle, and M. Sarstedt, "PLS-SEM: Indeed a silver bullet," Journal of Marketing Theory and Practice, vol. 19, no. 2, pp. 139-152, 2011.

[72] D. Gefen, D. Straub, and M. C. Boudreau, "Structural equation modeling and regression: Guidelines for research practice," Communications of the AIS, vol. 4, article 7, 2000.

[73] G. Abedi, F. Rostami, and A. Nadi, "Analyzing the dimensions of the quality of life in hepatitis B patientsusing confirmatory factor analysis," Global Journal of Health Acience, vol. 7, no. 7, pp. 22-31, 2015.

[74] D. H. Jonassen and J. Strobel, "Modeling for meaningful learning," Engaged Learning with Emerging Technologies, Dordrecht, DE: Springer, 2006, pp. 1-27.

[75] J. D. Novak, "Meaningful learning: The essential factor for conceptual change in limited or inappropriate propositional hierarchies leading to empowerment of learners," Science Education, vol. 86, no. 4, pp. 548-571, 2002.
[76] E. K. Loh, "What we know about expectancy-value theory, and how it helps to design a sustained motivating learning environment," System, vol. 86, p. 102119, 2019.

[77] National Science Foundation, Committee on equal opportunities in science and engineering 2011-2012 biennial report to congress broadening participation in America's STEM workforce. (2013). [Online]. Available: https://www.nsf.gov/od/oia/activities/ceose/reports/Full_2011-2012 CEOSE_Report_to_Congress_Final_03-04-2014.pdf

[78] C. F. Quigley, D. Herro, and A. Baker, "Moving toward transdisciplinary instruction: A longitudinal examination of STEAM teaching practices," STEAM Education, Cham, CH: Springer, 2019, pp. 143-164.

[79] N. A. Falk et al., "Expanding women's participation in STEM: Insights from parallel measures of self-efficacy and interests," Journal of Career Assessment, vol. 25, no. 4, pp. 571-584, 2017.

Copyright (C) 2020 by the authors. This is an open access article distributed under the Creative Commons Attribution License which permits unrestricted use, distribution, and reproduction in any medium, provided the original work is properly cited (CC BY 4.0).

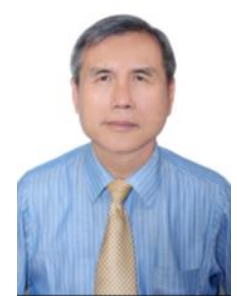

Jon-Chao Hong is a chair professor in Institute for Research Excellence in Learning Sciences, National Taiwan Normal University.

Dr. Hong was granted two "Outstanding Research Award" given by the Ministry of Science and Technology in Taiwan.

Dr. Hong's main research interests include digital learning, game-based learning, inquiry learning, STEAM education.

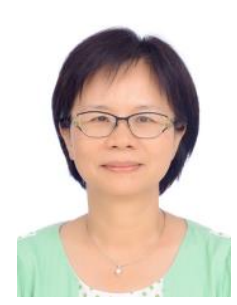

Mei-Lien Chen is a PhD student at the Department of Industrial Education, National Taiwan Normal University. She serves as a teacher at National Lan-Yang Girls' Senior High School.

Ms. Chen's main research interests include digital learning, physics education.

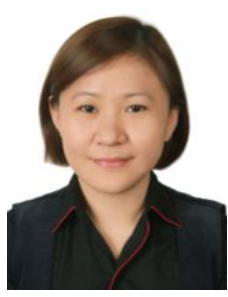

Chih-Mei Wang is a $\mathrm{PhD}$ student at the Department of Industrial Education, National Taiwan Normal University. She serves as a president at the Namchow foods consulting firm, Namchow Group.

Ms. Wang's main research interests include digital learning, Restaurant Management and vocational education.

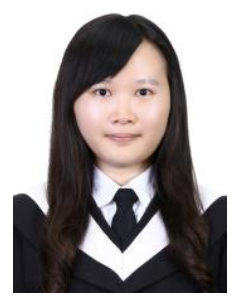

Jhen-Ni Ye is a $\mathrm{PhD}$ student at the Graduate Institute of Technological \& Vocational Education, National Taipei University of Technology. She serves as a research assistant at the Department of Industrial Education, National Taiwan Normal University.

Miss Ye's main research interests include digital learning, game-based learning, and vocational education.

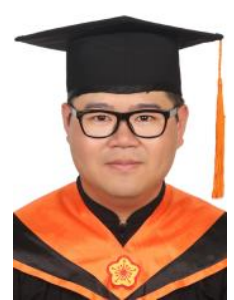

Jian-Hong Ye is a PhD candidate at the Department of Industrial Education, National Taiwan Normal University. He serves as a research assistant at the Institute for Research Excellence in Learning Sciences and Chinese Language and Technology Center, National Taiwan Normal University.

Mr. Ye's main research interests include digital learning, game-based learning, and design education. 